THE author of the work in the "Naturkräte" series, on "Die Insecten," noticed in NATURE for September 13 (p. 418) is not Dr. Georg Mayr, but Prof. Vitus Graber, of Czernowitz University, the well-known author of numerous interesting monographs on insect anatomy and histology.

TuE additicns to the Zoological Society's Gardens during the past week include a Robben Island Snake (Coronella phocarum) from South Africa, presented by the Rev. G. H. R. Fisk; a Chimpanzee (Troglodytes niger) from West Africa, a Leonine Monkey (Macacus leoninus) from Arracan, a White-fronted Capuchin (Cebus albifrons), a Laughing Gull (Larzes atricilla) from South America, deposited; a Greater Sulphur-crested Cockatoo (Cacatua galerita), from Australia, presented by Mr. G. S. S. Williams; two Red-backed Shrikes (Lanius collurio), Europsan, presented by Capt. F. H. Sahrn; two Spotted Turtle Doves (Tu,tur stratorssis), bred in the Gardens.

\section{INTRODUCTION AND SUCCESSION OF VERTEBRATE LIFE IN AMERICA ${ }^{1}$ \\ III.}

THE artiodactyles, or even-toed ungulates, are the most abundant of the larger mammals now living, and the group dates back at least to the lowest eocene. In every vigorous primitive type which was destined to survive many geological changes, there seems to have been a tendency to throw off lateral branches which became highly specialised and soon died out because they are unable to adapt themselves to new conditions. The narrow path of the persistent suilline type throughout the whole tertiary is strewn with the remains of such ambitious offshoots, winile the typical pig, with an obstinacy never lost, has held on in spite of catastrophes and evolution, and still lives in America to-day. The genus Platygonus is represented by several species, one of which was very abundant in the post-tertiary of North America, and is apparently the last example of a side branch, before the American suillines culminate in existing peccaries. The feet in this species are more specialised than in the living forms, and approach some of the peculiar features of the ruminants ; as, for example, a strong tendency to coalesce in the metapodial bones. The genus Flatygonus became extinct in the post-tertiary, and the later and existing species are all true peccaries. No authenticated remains of the genera Sus, Porcus, Phacochicrus, or the allied Hippotamus, the Old World suillines, have been found in America, although several announcements to that effect have been made.

In the series of generic forms between the lower eocene Eohynus and the existing Dicotyles, which I have very briefly discussed, we have apparently the ancestral line ending in the typical American suillines. Although the demonstration is not yet as complete as in the lineage of the horse, this is not owing to want of material, but rather to the fact that the actual changes which transformed the early tertiary pig into the modern peccary were comparatively slight, so far as they are indicated in the skeletons preserved, while the lateral branches were so numerous as to confuse the line. It is clear, however, that from the close of the cretaceous to the post-tertiary the bunodont artiodactyles were especially abundant on this Continent, and only recently have approached extinction.

The selenodont division of the artiodactyles is a more interesting group, and so far as we now know, makes its first appearance in the upper eocene of the west, although forms apparently transitional between it and the bunodonts occur in the dinoceras beds, or middle eocene. The most pronounced selenodont in the upper eocene is the Oromeryx, which genus appears to be allied to the existing deer family, or Cervide, and if so is the oldest known representative of the group. These facts are important, as it has been supposed, until very recently, that our eocene contained no even-hoofed mammals.

A most interesting line, that leading to the camels and llamas, separates from the primitive selenodont branch in the eocene, probably through the genus Parameryx. In the miocene, we find in Pobotherium and some nearly allied forms unmistakable indications that the cameloid type of ruminant had already

I Abstract of a lecture delivered at the Nashville meeting of the American ssociation, August 30, by Prof. O. C. Marsh. Continued from p. $47^{2}$ become partially specialised, although there is a complete series of incisor teeth, and the metapodial bones are distinct. In the pliocene the camel tribe was, next to the horses, the most abundant of the larger mammals. The line is continued through the genus Procamelus, and perhaps others, and in this formation the incisors first begin to diminish, and the metapodials to unite. In the post-tertiary we have a true Auchenia, represented by several species, and others in South America, where the alpacas and llamas still survive. From the eocene almost to the present time North America has been the home of vast numbers of the Camelide, and there can be little doubt that they originated here and migrated to the Old World.

The deer family has representatives in the upper miocene of Europe, which contains fossils strongly resembling the fauna of our lower pliocene, a fact always to be borne in mind in comparing the horizon of any group in the two continents. Several species of Cervidae, belonging to the genus Cosoryx, are known from the lower pliocene of the west, and all have very small antlers, divided into a single pair of tynes.

The proboscidians, which are now separated from the typical ungulates as a distinct orler, make their first appearance in North America in the lower pliocene, where several species of mastodon have been found. This genus occurs also in the upper plincene and in the post-tertiary, although some of the remains attributed to the latter are undoubtedly older. The pliocene species all have a band of enamel on the tusks, and some other peculiarities observed in the oldest mastodons of Europe, which are from essentially the same horizon. Two species of this genus have been found in South America, in connection with the remains of extinct llamas and horses. The genus Elephas is a later form, and has not yet been identified in this country below the upper pliocene, where one gigantic species was abundant. In the post-pliocene remains of this genus are numerous. The hairy mammoth of the Old World (Elephas primigenius) was once abundant in Alaska, and great numbers of its bones are now preserved in the frozen cliffs of that region. This species does not appear to bave extended east of the Rocky Mountains, or South of Columbia River, but was replaced there by the American elephant, which preferred a milder climate. Remains of the latier have been met with in Canada, throughout the Urited States, and in Mexico. The last of the American mastodons and elephants became extinct in the post-tertiary.

Perhaps the most remarkable mammals yet found in America are the Tillodontic, which are comparatively abundant in the lower and middle eocene. These animals seem to combine the characters of several different groups, viz., the carnivores, ungulates, and rodents. In the genus Tillotherium, the type of the order, and of the family Tillotheridce, the skull resembles that of the bears; the molar teeth are of the ungulate type, while the large incisors are very similar to those of rodents. The skeleton resembles that of the carnivores.

We now come to the highest group of mammals, the primates, which includes the lemurs, the apes, and man. This order has a great antiquity, and even at the base of the eocene we find it represented by several genera belonging to the lower forms of the group. In considering these interesting fossils it is important to have in mind that the lemurs, which are usually regarded as primates, although at the bottom of the scale, are only found at the present day in Madagascar and the adjacent regions of the globe. All the American monkeys, moreover, belong to one group, much above the lemurs, while the Old.World apes are higher still, and most nearly approach man.

In the lower eocene of New Mexico we find a few representatives of the earliest known primates, and among them are the genera Lemurazits and Limnotherinm, each the type of a distinct family. These genera became very abundant in the middle eocene of the West, and with them are found many others, all, however, included in the two families Lemuraviace and Limnotheride.

In the miocene lake basins of the West only a single species of the Primates has been identified with certainty. This was found in the oredoon beds of Nebraska and belongs to the genus Laopithecus, apparently related both to Limnotheridee and to some existing South American monkeys. In the pliocene and post-pliocene of North America no remains of primates have yet been found.

In the post-pliocene deposits of the Brazilian caves remains of monkeys are numerous, and mainly belong to extinct species of Callithrix, Cebzes, and Facchus, all living South American genera. Only one extinct genus, Protopithecuts, which em. 
braced animals of large size, has been found in this particular fauna.

It is a noteworthy fact that no traces of any anthropoid apes, or indeed of any Old World monkeys, have yet been detected in America. Man, however, the highest of the primates, has left his bones and his works from the Arctic Circle to Patagonia. Most of these specimens are clearly post-tertiary, although there is considerable evidence pointing to the existence of man in our pliocene. All the remains yet discovered belong to the wellmarked genus Homo, and apparently to a single species, at present represented by the American Indian.

In this rapid review of mammalian life in America, from its first known appearance in the trias down to the present time, I have endeavoured to state briefly the introduction and succession of the principal forms in each natural group. If time permitted, I might attempt the more difficult task of trying to indicate what relations these various groups may possibly bear to each other; what connection the ancient mammals of this continent have with the corresponding furms of the Old World; and, most im. portant of all, what real progre is mammalian life has here made since the beginning of the eocene. As it is, I can only say in summing up, that the marsupials are clearly the remnants of a very ancient fauna, which occupied this continent millions of years ago, and from which the other mammals were doubtless all derived, although the direct evidence of the transformation is wanting.

The relations of the American primates, extinct and recent, to those of the other hemisphere, offer an inviting topic, but it is not in my present province to discuss them in their most sug. gestive phases. As we have here the oldest and most generalised members of the group, so far as now known, we may justly claim America for the birth-place of the order. That the development did not continue here until it culminated in man, was due to causes which at present we can only surmise, alchough the genealogy of other surviving groups gives some data towards a solution. Why the Old World apes, when differentiated, did not come to the land of their earlier ancestry, is readily explained by the then intervening oceans, which likewise were a barrier to the return of the horse and rhinoceros.

Man, however, came; doubtless first across Behring's Straits and at his advent bevame part of our fauna, as a mammal and primate. In these relations alone it is my purpose here to treat him. The evidence, as it stands to-day, although not conclusive, seems to place the first appearance of man in this country in the pliocene, and the best proof of this has been found on the Pacific coast. During several visits to that region many facts were brought to my knowledge which render this more than probable. Man at this time was a savage, and was doubtless forced by the great vo!canic outbreaks to continue his migration. This was a first to the south, since mountain chains were barriers on the east. As the native horses of America were now all extinct, and as the early man did not bring the Old World animal with him, his migrations were slow. I believe, moreover, that his slow progress towards civilisation was in no small degree due to this same cause, the absence of the hax e.

It is far from my intention to add to the many theories extant in regard to the early civilisations in this country, and their connections with the primitive inhabitants or the later Indians, but two or three facts have lately come to my knowledge which I think worth mentionirg in this connection. On the Columbia River, I have found evidence of the former existence of inhabitants much superior to the Indians at present there, and of which no tradition remains. Among many stone carvings which I saw there were a number of heads which so strongly resemble those of apes that the likeness at once suggests itself. Whence came these sculptures, and by whom were they made? Another fact that has interested me very much is the strong resemblance between the skulls of the typical mound-builders of the Mississippi Valley and those of the Pueblo Indians. I had long been familiar with the former, and when I recently saw the latter it required the positive assurance of a friend who had himself collected them in New Mexico to convince me that they were not from the mounds. A third fact, and I leave man to the archæologists, on whose province $\mathrm{I}$ am even now trenching. In a large collecii in of mound-builders' pottery, over a thousand specimens, which I have recently examined with some care, I found many pieces of elaborate workmanship so nearly like the ancient water-jars from Peru that no one could fairly doubt that some intercourse had taken place between the widelyseparated people that made them.

The oldest known remains of man on this continent differ in no important characters from the bones of the typical Indian, although in some minor details they indicate a much more primitive race. These early remains, some of which are true fossils, resemble much more closely the corresponding parts of the highest Old World apes, than do the latter our tertiary primates, or even the recent American monkeys. Various living and fossil forms of Old World primates fill up essentially the latter gap. The lesser gap between the primitive man of America and the anthropoid apes is partially closed by still lower forms of men, and doubtless also by higher apes, now extinct. Analogy, and many facts as well, indicate that this gap was smaller in the past. It certainly is becoming wider now with every generation, for the lowest races of men will soon become extinct, like the Tasmanians, and the highest apes cannot long survive. Hence the intermediate forms of the past, if any there were, become of still greater importance. For such missing links, we must look to the caves and later tertiary of Africa, which I regard as now the most promising field for exploration in the Old World. America, even in the tropics, can promise no such inducements to ambitious explorers. We have, however, an equally important field, if less attractive, in the cretaceous mammals, which must have left their remains somewhere on this continent. In these two directions, as I believe, lie the most important future discoveries in palaeontology.

As a cause for many changes of structure in mammals during the tertiary and post-tertiary, I regard as the most potent, natural selection, in the broad sense in which that term is now used by American evolutionists. Under this head, I include not merely a Malthusian struggle for life among the animals themselves, but the equally important contest with the elements, and all surrounding nature. By changes in the environment, migrations are enforced, slowly in some cases, rapidly in others, aad with change of locality must come adaptation to new conditions, or extinction. The life history of tertiary mammals illustrate: this principle at every stage, and no o: her explanation meets the facts.

The real progress of mammalian $3 i f e$ in America, from the beginning of the tertiary to the present, is well illustrated by the brain-growth, in which we have the key to many other changes. The earliest known tertiary mammals all had very small brains, and in some forms this organ was proportionaily less than in certain reptiles. There was a gradual increase in the size of the brain during this periof, and it is interesting to find that this growth was mainly confined to the cerebral hemispheres, or higher portion of the brain. In most groups of mammals the brain has gradually become more convoluted, and thus increased in quality as well as quantity. In some, also, the cerebellum and olfactory lobes, the lower parts of the brain, have even diminished in size. In the long struggle for existence during tertiary time the big brains won, then as now; and the increasing power thus gained rendered useless many structures inherited from primitive ancestors, but no longer adapted to new conditions.

Another of the interesting changes in mammals during tertiary time was in the tecth, which were gradually modified with other parts of the structure. The primitive form of tooth was clearly a cone, and all others are derived from this. All classes of vtr. tebrates below mammals, namely, fishes, amphibians, reptiles, and birds, have conical teeth, if any, or some simple modification of this form. The edentates and cetaceans with teeth retain this type, except the zeuglodonts, which approach the dentition of aquatic carnivores. In the higher mammals the incisors and canines retain the conical shape, and the premolars have only is part been transformed. The latter gradually change to the more complicated molar pattern, and hence are not reduced molars, but transition forms from the cone to more complex types. Most of the early tertiary mammals had forty-foux teeth, and in the oldest forms the premolars were all unlike the molars, while the crowns were short, covered with enamel, and without cement. Each stage of progress in the differentiation of the animal was, as a rule, marked by a change in the teeth, one of the most common being the transfer, in form at least, of a premolar to the molar series, and a gradual lengthening of the crown. Hence it is often easy to decide from a fragment of a jaw, to what horizon of the tertiary it belongs. The fossil horses of this period, for example, gained a grinding tooth for each toe they lost, one in each epoch. In the single-toed existing horses all the premolars are like the molars, and the process is at an end. Other dental transformations are of equal interest, but this illustration must suffice.

The changes in the limbs and feet of mammals during the same period were quite as marked. The foot of the primitive 
mammal was doubtless plantigrade, and certainly five-toed. Many of the early tertiary forms show this feature, which is still seen in some existing forms. This generalised foot became modified by a gradual loss of the outer toes and increase in size of the central ones, the reduction proceeding according to systematic methods, differing in each group. Corresponding changes took place in the limb bones. One result was a great increase in speed, as the power was applied so as to act only in the plane of motion. The best effect of this specialisation is seen to-day in the horse and antelope, each representing a distinct group of ungulates with five-toed ancestors.

If the history of American mammals, as I have briefly sketched it, seems as a whole incomplete and unsatisfactory, we must remember that the genealogical tree of this class has its trunk and larger limbs concealed beneath the débris of mesozoic time, while its roots doubtless strike so deeply into the palrozoic that for the present they are lost. A decade or two hence we shall probably know something of the mammalian fauna of the cretaceous, and the earlier lineage of our existing mammals can then be traced with more certainty.

The results I have presented to you are mainly derived from personal observation, and since a large part of the higher vertebrate remains found in this country have passed through my hands, I am willing to assume full responsibility for my presentation of the subject.

For our present knowledge of the extinct mammals, birds, and reptiles of North America, science is especially indebted to Leidy, whose careful, conscientious work has laid a secure foundation for our vertebrate palieontology. The energy of Cope has brought to notice many strange forms, and greatly enlarged our literature. Agassiz, Owen, Wyman, Baird, Hitchcock, Deane, Emmons, Lea, Allen, Gibbes, Jefferson, DeKay, and IIarlan deserve honourable mention in the history of this branch of science. The South American extinct vertebrates have been described by Lund, Owen, Burmeister, Gervais, Huxley, Flower, Desmarest, Aymard, Pictet, and Nodot. Darwin and Wallace have likewise contributed valuable information on this subject, as they have on nearly ali forms of life.

In this long history of ancient life I have said nothing of what life itself really is. And for the best of reasons, because I know nothing. Here at present our ignorance is dense, and yet we need not despair. Light, heat, electricity and magnetism, chemical affinity, and motion are now considered different forms of the same force; and the opinion is rapidly gaining ground that life, or vital force, is only another phase of the same power. Possibly the great mystery of life may thus be solved, but whether $i$ : be or not, a true faith in science admits no limit to its search for truth.

THE GERMAN ASSOCIATION AT MUNICH TIIE fiftieth meeting of the German Association of Naturalists and Physicians began on September $I 7$ by a large assembly of visitors in the old Town Hall at Munich. The meeting this year assumed quite a national character. Although in the programme its scientific character was principally considered, and pleasure trips, banquets, \&c., had been reduced to the most modest proportions in comparison with former years, yet the aspect of the city of Munich, and of all the edifices that were in any way connected with the meeting, was a festive one. Some 2,000 visitors had arrived, and the Town Hall on the night of the I 7 th was crowded to suffocation. The authorities of the city gave a grand Keller-Fest in honour of the visitors on the 20 th, which was attended by over 5,000 guests.

The first general meeting was opened by Prof. von Pettenkofer on the morning of the I8th inst. In a short address the professor announced that His Majesty the King had intended to serd his royal greeting to the assembled men of science through H.R.H. Duke Carl Theodor, of Bavaria (brother to the Empress of Austria), kut that the cluke had suddenly been called to Dresden through the death of the dowager Queen of Saxony. In his absence His Majesty had intrusted the secretaries with this honourable message. After other congratulations Dr. von Pettenkofer delivered his inaugural address. $\mathrm{He}$ reminded the assembly that the present was a jubilee meeting, and then gave a retrospect of the growth of the Association since its foundation. The first meeting took place at Leip. zig on September 18, 1822, when, following the invitation of Prof. Oken, twenty scientific men assembled and founded the Society. A paragraph of the statutes prescribed that the meetings should always begin on September 18 , and should last several days. Under the political circumstances of that time and with the means of conveyance then existing the modest number of twenty members was considered a fair beginning. The next meeting occurred at Halle with thirty.four members, the third at Wuirzburg with thirty-six, the fourth at Frank fort-on-Maine with $I$ ro, the fifth at Dresden with $1 \mathrm{I} 6$, the sixth at Munich with 156 , and the seventh at Berlin in 1828 , when 464 members were present. The Association steadily increased and the meetings were held annually unless prevented by war or epidemics. The last meeting at Hamburg numbered over 2,000 members. Little by little a division of labour took place, and out of the seven original sections twenty-five have now resulted.

After speaking of the progress made by man as compared with the lower animals, Prof. Pettenkofer said-If knowledge is power, and nobody will doubt this, then amongst sciences natural science is certainly destined to play a great part, perhaps the greatest, in the history and culture of mankind. . . Natural science has but to look for facts and truths, and need never busy itself about the immediate practical application of what has been found, because for them alone it deserves the sympathy of the entire civilised world, and the means necessary for its culture and development. No investment of capital bears higher interest. Finally, the speaker recalled the memory of Prof. Ludwig Lorenz Oken, the founder of the association and the author of the statutes which, with but a single and trifling exception are still in force to-day. He praised the patriotism of Oken, and regretted that he died before the reestablishment of the United German Empire.

At the end of the address, the assembly, at the request of Dr. von Pettenkofer, rose from their seats in honour of the memory of Oken.

Then followed the first scientific lecture, which was delivered by Prof. Waldeyer (Strassburg). He spoke on Karl Ernst von Faer and his Influence on Natural Science, giving an elaborate memoir of the late great naturalist, to whom we owe many of the bases of the present theory of evolution. Prof. Dr. Haeckel then delivered his address On the Evolution Theory at the Present Time, which we give elsewhere.

At the second general mecting, on the 20 ih, the choice of a place of meeting was made for next year, Cassel being selected, with Doctors Stilling and Gernau as secretaries. Duke Carl Theodor of Bavaria, himself an able ophthalmologist, took the chair in lieu of Dr. Pettenkofer, and again welcomed the assembly, in the name of the kingdom of Bavaria, in an interesting speech. Then followed the address of the eminent botanist, Prof. Dr. Nägeli, of Munich, "On the Limits of Nvatural Knowledge." He pointed out that many naturalists, when asked about the limits of natural knowledge, and thinking a solution by principles insufficient, simply reply that faith begins where knowledge ends. Humanity faces the whole of nature, masters new domains constantiy by dint of meditation; the empire of knowledge thus always increases in extent, and that of faith decreases as constantly. But this solution does not satisfy our interest. We would wish to know particularly whether the limits of natual knowledge can be determined at all, and how far we can penetrate into nature. The solution of this question is determined by three crnditions:-(I) By the condition and capacity of the investigating Self; (2) by the condition and accessibility of nature; and (3) by the demands which we make from knowledge. With regard to the first point, the undoubted fact is decisive that our power of thinking, in whatever condition it may be, can but give us nature as we perceive her with our five senses, and even this again not in her full extent and completeness, but only as far as we perceive her in the present. We see and hear only what is in the present; now as the organs of our senses are more or less sensitive for the one or the other perception, Darwin's ingenious idea that in nature only so many phenomena attained full development as were useful to the individual bearer, is fully justified; on the other hand it is very probable that many molecular forces exist of which we have no idea, simply because we cannot perceive them with our senses. The limited capacity of the I allows us only an extremely fragmentary knowledge of the universe. With reference to the second point, the condition and accessibijity of nature, we can easily perceive the limit; for man it rests in space and time. The infinity of space and time, and its consequences, are insuperable for us, and nature is everywhere uninvestigable where she becomes eternal or infinite, and therefore she can never be entirely investigated. The naturalist must therefore always bear in mind that all his investigations are re. stricted to natural limits, otherwise he will lose himself in ground- 